\title{
Use of Wastewaters from Ethanol Distilleries and Glycerol Mixtures for Microbial Oils Production
}

\author{
Evelyn Faife Perez*, Aidin Martínez, Yanay Martínez, Nayra Ochoa, Amaury Álvarez, \\ Juana M. Chanfon, Mayrelis Mesa
}

Biotechnology Division, Cuban Institute for Research Sugarcane by-Products (ICIDCA), Havana, Cuba

\section{Email address:}

evelyn.faife@icidca.azcuba.cu (E. F. Perez), aidin.martínez@icidca.azcuba.cu (A. Martínez), yanay.martinez@icidca.azcuba.cu (Y. Martínez), nayra.ochoa@icidca.azcuba.cu (N. Ochoa), amaury.alvarez@icidca.azcuba.cu (A. Álvarez), juana.chanfon@icidca.azcuba.cu (J. M. Chanfon), mayrelis.mesa@icidca.azcuba.cu (M. Mesa)

${ }^{*}$ Corresponding author

\section{To cite this article:}

Evelyn Faife Perez, Aidin Martínez, Yanay Martínez, Nayra Ochoa, Amaury Álvarez, Juana M. Chanfon, Mayrelis Mesa. Use of Wastewaters from Ethanol Distilleries and Glycerol Mixtures for Microbial Oils Production. American Journal of Bioscience and Bioengineering. Vol. 4, No. 4, 2016, pp. 41-48. doi: 10.11648/j.bio.20160404.11

Received: August 26, 2016; Accepted: October 29, 2016; Published: November 23, 2016

\begin{abstract}
Biodiesel has become more attractive in recent years because of its environmental benefits. One way to reduce the high cost of biodiesel is by lowering the cost of raw materials specially oils. Recently, much attention has been paid to the development of microbial oils through cultures of oleaginous microorganisms in inexpensive substrates as the wastewaters of some food industries and the crude glycerol from biodiesel production itself. Thus, cultivation of oleaginous yeasts in glycerolbased media is attracting great interest and natural biodiversity is increasingly explored to identify novel oleaginous species recycling this carbon source for growth and lipid production. Identification of oleaginous yeasts and the evaluation in glycerol and vinasse mixtures was employed to produce biomass enriched in microbial lipids and to remove nutrients from vinasse simultaneously. The fatty acid composition of the lipids was similar to that from plant oils and other microbial lipids therefore they can be used as raw material for feed additives and biodiesel production.
\end{abstract}

Keywords: Vinasse, Glycerol, Lipids, Biodiesel, Oleaginous

\section{Introduction}

The conventional method for biodiesel production is the transesterification of plant oils with methanol. However, the cost of biodiesel is currently more expensive than that of conventional diesel due to the high cost share $(70-85 \%)$ of the raw material. Increasing interest is being generated to explore ways to reduce the cost of the raw materials.

Recently, the interest in some microorganisms called oleaginous or "oil bearing" has been renewed, as a source for oils and fats. Several algae, yeasts and bacteria are capable of accumulating up to $70 \%$ of their dry weight as oil in the form of triacylglycerol. The possibilities of use this oil as a feedstock for biodiesel production is considerable [1].

Vinasses are the major effluent from the bioethanol industry and represent a major environmental problem. This black liquid is produced at a rate of 10 to 15 liters per liter of distilled ethanol and it is a mixture of water, organic and inorganic compounds. The chemical oxygen demand of Cuban vinasse is around $50000-60000 \mathrm{mg} / \mathrm{L}$.

Currently, most of the vinasse that results from ethanol production is being used as fertiliser due to its organic matter content and nutrients as potassium and nitrogen. A problem occur when the nearest fields to the distillery receive a slop dose that overcomes the assimilation capacity of the soil, reducing the alkalinity destroying the crops, causing manganese deficiency and inhibiting seed germination.

The industrial application of biodiesel production has been stimulated by the production of high amounts of concentrated glycerol residual water, as the main by-product of the transesterification process applied in biodiesel. Its disposal constitutes an economic and ecological burden. This aspect can be ameliorated, however, by glycerol recycling to lipid 
production.

Therefore, the utilisation of raw glycerol and vinasse as feedstock for microbial oil production seems to be an interesting alternative and "environmentally-friendly" strategy, aiming to control soil deterioration, to improve the economics of biodiesel industry, to produce SCP rich in oils as a supplement in animal feeding as well as to upgrade glycerol waste streams.

The objectives of this study is evaluate the potential of selected oleaginous yeasts to growth and accumulate lipids in vinasse and glycerol mixtures to propose this media as a feedstock for microbial oil production and as a solution to environmental contamination

\section{Materials and Methods}

\subsection{Screening of Oleaginous Yeasts}

The samples were collected from sugarcane fields and molasses from a sugar mill in the central region of Cuba. Twenty (20) $\mathrm{g}$ of samples were added to $100 \mathrm{~mL}$ of distilled water (DW). Mixtures were homogenised during 30 minutes at $150 \mathrm{rpm}$ and $30^{\circ} \mathrm{C}$. Serial dilutions in distilled water were made until $10^{-3}$ and then $0.1 \mathrm{~mL}$ diluted culture was isolated on YPG agar medium using spread plate technique for 48 $72 \mathrm{~h}$ at $30^{\circ} \mathrm{C}$. Interesting colonies were examined in a microscope, isolated and purified by Harrigan method [2].

Total yeast strains were stained with Sudan Black B technique [3, 4] and observed under a phase contrast microscope on oil immersion for the presence of blue or greyish coloured fat globules within the cell lipids. The yeast strains showing fat globules within the cells were preselected for further assays.

\subsection{Identification of Oleaginous Yeasts}

A primary identification was performed using two chromogenic media: Sabouraud and a chromogenic medium designed for some Candida species by BioCen (Cuba), similar to CHROMagar Candida ${ }^{\circledR},[5]$. Yeasts were cultured at $30^{\circ} \mathrm{C}$ during $24 \mathrm{~h}$ in this medium and identification was determined by visual inspection of blue and pink colours.

Identification of preselected yeast strains was made by API 20C System. Molten $\left(50^{\circ} \mathrm{C}\right)$ API basal medium ampoules were inoculated with yeast colonies, and the suspension was standardised to a density below 1+ (lines can be clearly distinguished) on a Wickerham card.

Each cupule was inoculated, and the trays were incubated for $72 \mathrm{~h}$ at $30^{\circ} \mathrm{C}$. Cupules showing turbidity significantly heavier than that of the negative control cupule ( 0 cupule) were considered positive. Identification was made by generating a microcode and using the API $20 \mathrm{C}$ and software ApiWeb StandAlone®.

\subsection{Yeast Inoculation, Flasks and Bioreactor Culture}

The oleaginous yeast colonies were initially streaked onto YEPD slant and grown for 2 days. After that, cells were transferred to $250-\mathrm{mL}$ Erlenmeyer flasks containing $50-\mathrm{mL}$ of inoculation medium (YPG) at $30^{\circ} \mathrm{C}$ on a rotary shaker at $150 \mathrm{rpm}$ for 48 hours.

$10 \mathrm{mLs}$ of inoculum was transferred to $90 \mathrm{ml}$ of a primary medium compound by pure glycerol medium (20 g/l glycerol, purity 99.5\%, (BDH Prolabo), $10 \mathrm{~g} / 1$ yeast extract, $20 \mathrm{~g} / 1$ peptone) to propagate cells for different assays. All experiments in flasks and bioreactors were made using a $10 \%$ $(\mathrm{v} / \mathrm{v})$ of cells grown in exponential phase in this medium $\left(10^{8}\right.$ cell $/ \mathrm{mL}$ and $95 \%$ of viability)

The effect of glycerol concentration at 20, 40, 60, 80, 100 and $120 \mathrm{~g} / \mathrm{L}$ as carbon source on cell growth of selected yeast strains in spread-plates and flasks was investigated. Plates were inoculated with $20 \mathrm{~mL}$ of $10^{-4}, 10^{-5}$ and $10^{-6}$ diluted precultures inoculums of $24 \mathrm{~h}$ and incubated during $24-72 \mathrm{~h}$ at $30^{\circ} \mathrm{C}$. The study in $500 \mathrm{mLs}$ erlenmyer flasks was made by triplicate at at $30^{\circ} \mathrm{C}$ and $150 \mathrm{rpm}$ during 120 hours.

Taking advantage of the experience of ICIDCA (Cuba) in the industrial production of single cell protein (SCP) using molasses/vinasse mixtures as culture medium [6-9], experiments in $4 \mathrm{~L}$ bioreactors (Marubishi MD 5, Tokyo, Japan) were done using a nitrogen-limited medium (30\% of nitrogen requirement) containing $\left(\mathrm{NH}_{4}\right)_{2} \mathrm{SO}_{4} \quad 0.92$; $\left(\mathrm{NH}_{4}\right)_{2} \mathrm{HPO}_{4} 1.22$ in $\mathrm{g} / \mathrm{L}$, prepared with a vinasse/glycerol mixture adjusted to $75000 \mathrm{mg} / \mathrm{L}$ of total (COD with a 70:30 ratio, where $70 \%$ was the vinasse contribution and $30 \%$ of glycerol).

Fermentation parameters were fixed at $600 \mathrm{rpm}$, air supply of $1.2 \mathrm{vvm}$ (air volume per medium volume per minute) and $\mathrm{pH}$ 4.0. The experiments were performed during $24 \mathrm{~h}$ with two replicates and samples analysed per duplicate for dry biomass, chemical oxygen demand and lipid content.

\subsection{Determination of Yeast Dry Biomass}

Aliquots of 5-mL cultures were harvested by centrifugation at $5000 \times \mathrm{g}$ for $5 \mathrm{~min}$. Collected biomass was washed twice with $5-\mathrm{mL}$ of distilled water. The biomass was determined gravimetrically in an infrared balance (Sartorius $\mathrm{GmbH}$, Germany) at $105^{\circ} \mathrm{C}$.

\subsection{Chemical Oxygen Demand}

It was determined according to Conde method [10]. Briefly, 1-mL of centrifuged fermented medium was poured into a reflux conical flask of $25-\mathrm{mL}$ and $0,04 \mathrm{~g}$ of $\mathrm{HgSO}_{4}$ (II). Finally, $1-\mathrm{mL}$ of $0.04 \mathrm{M}$ of potassium dichromate and several glass pearls were added, the latter to avoid bumping, and slowly, 3-mL of sulphuric acid (d=1.84) with 9,9 $\mathrm{g} / \mathrm{L}$ of $\mathrm{AgSO}_{4}$. The reaction mixture is refluxed for $12-15 \mathrm{~min}$, and, after cooling, 100-mL of distilled water was added. The excess of dichromate is determined with diammonium ferrous sulphate with ferroin as indicator. A blank with 1-mL of distilled water was run in parallel.

\subsection{Determination of Lipid Content}

Lipids were extracted, dried and weighed and the method of Bligh and Dyer [11] with slight modifications was used. A 50-mL sample was centrifuged at $5000 \mathrm{xg}$ for $5 \mathrm{~min}$, after 
which the yeast was washed twice with $50-\mathrm{mL}$ of distilled water and dried overnight, then 1 gram of dry biomass was added into $10-\mathrm{mL}$ of $4 \mathrm{M} \mathrm{HCl}$, and incubated at $60^{\circ} \mathrm{C}$ for 1 to $2 \mathrm{~h}$. The acid-hydrolysed mass was stirred with $10-\mathrm{mL}$ of chloroform/methanol mixture $(1: 3)$ at room temperature for 2 to $3 \mathrm{~h}$, followed by centrifugation at $5000 \mathrm{xg}$ for $5 \mathrm{~min}$ to separate the aqueous and organic phases. Finally, the lower phase containing the lipids was recovered with a Pasteur pipette, and evaporated under vacuum for $10 \mathrm{~min}$. The dry lipids were weighed.

\subsection{Fatty Acid Derivatisation for Gas Chromatography}

A sample of $150 \mathrm{mg}$ of oil was poured into a dry test tube and $5 \mathrm{~mL}$ of $10 \%$ methanol solution of sodium methoxide were added and hermetically sealed. Then, the tube is then placed in a thermostatic water bath at $85^{\circ} \mathrm{C}$ for $2 \mathrm{~h}$ with occasional vigorous stirring. After that, the tube is cooled at room temperature and $5 \mathrm{~mL}$ of $\mathrm{n}$-hexane and $5 \mathrm{~mL}$ of distilled water were added and the sample stirred for $1 \mathrm{~min}$. The mixture is separated into two phases and $4 \mathrm{~mL}$-aliquot of the upper phase is extracted and placed in a dry tube. The lower phase is discarded. The extract is mixed with $5 \mathrm{~mL}$ of $\mathrm{n}$-hexane and $5 \mathrm{~mL}$ of $\mathrm{N}$ methanol solution of sodium hydroxide, and then the tube is sealed and placed in a rotary shaker for $1 \mathrm{~min}$. The solution splits into two phases and from the upper one a $2 \mathrm{~mL}$-aliquot was extracted and the solvent evaporated under vacuum in a centrifuge. Finally, the fatty acid methyl esters were dissolved in acetone for gas chromatography.

For fatty acid characterisation, a GC-17A Shimadzu chromatograph provided with AOC-20S auto-injector coupled to a MS-QP5050A mass spectrophotometer were employed. The instrument has an electronic ionisation source and a quadrupole analyser. A DB-1 non polar $30 \mathrm{~m}$ x 0.25 mm capillary column was used.

\section{Results and Discussion}

\subsection{Screening and Identification of Yeasts}

Seventy three yeast strains were isolated from soils and molasses and cultivated in YPG medium at $\mathrm{pH}$ (4-5.5) with chloramphenicol $1 \%$. Seven yeast strains were found positive from results of Sudan Black B technique. L/3-74-21 and L/374-22 yeasts developed a blue colour when were culture in BioCen medium and L/24-25-1, L/24-26-1, L/24-26-2 and L/24-26-3 shown a pink coulor in Sabouroud medium, wich are typical colour of Candida sp. and Rhodotorula sp. in these media, respectively (Figure 1).

According to the results of identification by API 20 AUX System most of the strains belong to Candida and Rodotorula sp. (Table 1). This amount is probably related to the adaptability of these genus to many ecosystems [12]. The capacity of these genus to produce lipids has been previously reported by several researchers [13-19].
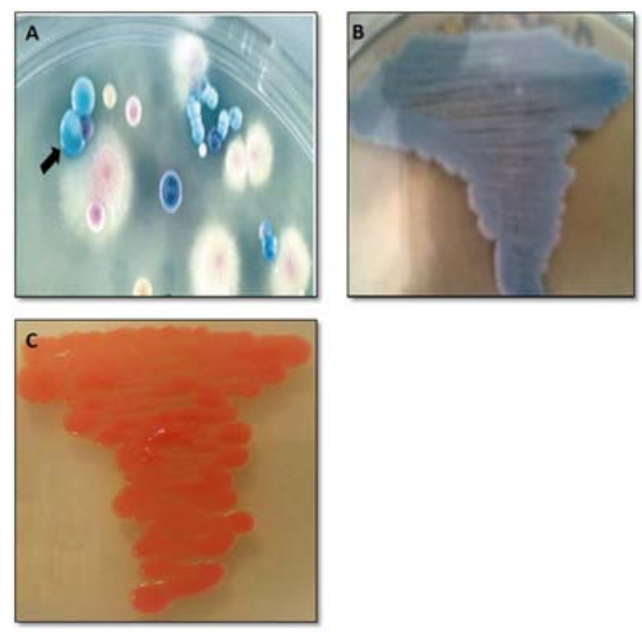

Figure 1. Growth in plates of the strains in Sabouraud and BioCen media (A: isolated strain yeasts from molasse, B: purified L/3-74-22 strain in BioCen medium and C: purified L/24-26-1 strain in Sabouraud medium).

Table 1. Results of the yeast strains identification by API 20C System according to different substrates consumption.

\begin{tabular}{|c|c|c|c|c|c|c|c|}
\hline Carbon Source & L/3-74-21 & L/3-74-22 & $L / 25-7-20$ & L/24-25-1 & L/24-26-1 & L/24-26-2 & L/24-26-3 \\
\hline Glucose & + & + & + & + & + & + & + \\
\hline Glycerol & + & + & - & + & + & + & + \\
\hline L-Arabinose & - & - & - & + & + & + & + \\
\hline Xylose & - & + & - & + & + & + & + \\
\hline D-galactose & - & + & + & - & + & + & + \\
\hline D-Lactose & - & - & - & + & - & - & - \\
\hline Identification & $A$ & $A$ & $B$ & $C$ & $D$ & $D$ & $D$ \\
\hline
\end{tabular}

\subsection{Influence of Glycerol Concentration}

It has been demonstrated that glycerol is a good substrate for different yeast species [20-23]. Others researchers found that only a few species of Candida, Cryptococcus, Pichia, Kluyveromyces and Saccharomyce., are capable to consume more than $90 \%$ glycerol and were also able to accumulate lipids [24]. Recently some experiments demonstrated the assimilation capacity of crude glycerol from biodiesel industrial waste of some yeasts species as Rhodotorula glutinis, Candida aloleophila, Candida curvata, Candida pulcherrima, Yarrovia lipolytica, Cryptococcus curvatus and Pichia membranifaciens [22, 25-27].

Visual inspection of the plate cultures using glycerol as unique carbon source shown that there was no growth inhibition until $120 \mathrm{~g} / \mathrm{L}$ of glycerol concentration. One $C$. 
tropicalis strain (L/3-74-22) and one $R$. mucilaginosa (L/2426-1) strain were selected to continue the experiments. The biomass concentration, substrate yields and specific growth rate of $C$. tropicalis and $R$. mucilaginosa cultured in flasks after $24 \mathrm{~h}$ are shown in Table 2 . The results shown that $R$. mucilaginous strain reached the highest value of biomass concentration, yield and specific growth rate in evaluated glycerol concentrations.

This results matches with a screening reported by Taccari [28] using anothers $C$. tropicalis and $R$ mucilaginosa strains where $R$ mucilaginousa cell densities were almost double respect $C$. tropicalis on pure glycerol at $20 /$ L. Specific growth rate value of $C$. tropicalis $\mathrm{L} / 3-74-22$ strain at $20 \mathrm{~g} / \mathrm{L}$ of glycerol was lower than others values of Candida $s p$. $(0,14$ $\left.-0,17 \mathrm{~h}^{-1}\right)$. In case of $R$. mucilaginosa $\mathrm{L} / 24-26-1$, the specific growth rate reported was very similar to Rhodotorula mucilaginosa DiSVA $6094\left(0,14 \mathrm{~h}^{-1}\right)$ and Rhodotorula mucilaginosa DiSVA C7.1 $\left(0,16 \mathrm{~h}^{-1}\right)$.

Several researchers have demonstrate that cell growth and lipid content of different oleaginous yeast cells is lower in glycerol respect to other carbon source to the same concentration and showed their positive effect when it is used simultaneously with another energy source as xylose [29, 30].

Table 2. Comparative fermentation parameters of C. tropicalis L/3-74-22 and R. mucilaginosa L/24-26-1 strains a in the presence of different glycerol concentration in $500 \mathrm{ml}$ flasks and $30^{\circ} \mathrm{C}$.

\begin{tabular}{|c|c|c|c|c|c|c|}
\hline \multirow{3}{*}{$\begin{array}{l}\text { Glycerol conc. } \\
(\mathrm{g} / \mathrm{l})\end{array}$} & \multirow{2}{*}{\multicolumn{2}{|c|}{$\begin{array}{l}\text { Biomass conc. } \\
(\mathrm{g} / \mathrm{l})\end{array}$}} & \multirow{2}{*}{\multicolumn{2}{|c|}{$\mathbf{Y x} / \mathbf{s}$}} & \multirow{2}{*}{\multicolumn{2}{|c|}{$\begin{array}{l}\mu \\
\left(h^{-1}\right)\end{array}$}} \\
\hline & & & & & & \\
\hline & $\mathrm{L} / 3-74-22$ & $\mathrm{~L} / 24-26-1$ & $\mathrm{~L} / 3-74-22$ & $\mathrm{~L} / 24-26-1$ & $L / 3-74-22$ & $\mathrm{~L} / 24-26-1$ \\
\hline control & $10,6 \pm 1,8$ & $12,2 \pm 0,4$ & $0,530 \pm 0,03$ & $0,496 \pm 0,02$ & $0,11 \pm 0,03$ & $0,25 \pm 0,05$ \\
\hline 20 & $4,9 \pm 1,1$ & $7,34 \pm 0,3$ & $0,245 \pm 0,12$ & $0,279 \pm 0,01$ & $0,07 \pm 0,02$ & $0,15 \pm 0,01$ \\
\hline 40 & $7,5 \pm 1,3$ & $9,15 \pm 0,2$ & $0,156 \pm 0,05$ & $0,189 \pm 0,03$ & $0,09 \pm 0,01$ & $0,16 \pm 0,01$ \\
\hline 60 & $9,1 \pm 2,2$ & $10,3 \pm 1,6$ & $0,122 \pm 0,03$ & $0,144 \pm 0,05$ & $0,10 \pm 0,01$ & $0,18 \pm 0,02$ \\
\hline 80 & $10,2 \pm 2,1$ & $12,1 \pm 1,9$ & $0,107 \pm 0,04$ & $0,133 \pm 0,02$ & $0,10 \pm 0,01$ & $0,22 \pm 0,01$ \\
\hline 100 & $11,6 \pm 0,2$ & $15,7 \pm 1,4$ & $0,101 \pm 0,01$ & $0,143 \pm 0,04$ & $0,11 \pm 0,01$ & $0,20 \pm 0,03$ \\
\hline 120 & $12,7 \pm 0,8$ & $17,7 \pm 2,1$ & $0,100 \pm 0,02$ & $0,137 \pm 0,01$ & $0,12 \pm 0,02$ & $0,26 \pm 0,02$ \\
\hline
\end{tabular}

\subsection{Evaluation in Vinasse/Glycerol Mixture with Nitrogen Limitation}

The evaluation of $C$. tropicalis and $R$. mucilaginosa strains in this mixture showed that both yeasts were able to grow and accumulated lipids under these culture conditions, nevertheless their cell growth parameters were very different. The results of cell growth parameters and lipid content shown in Table 3 demonstrated that there was a marked difference between the behaviour of each strain. C. tropicalis achieved higher values of biomass concentration, specific growth rate and COD removal while the lipid content were higher in $R$. mucilaginosa.

Oleaginous microorganisms start to produce lipids when a growth required nutrient, mostly nitrogen, is exhausted in the medium $[31,32]$. The excess carbon is then channeled into lipid production. Accordingly, it has been shown that the lipid content is constantly low when nitrogen is present in the culture medium. Thus, the carbon to nitrogen ratio $(\mathrm{C} / \mathrm{N}$ ratio) of the culture medium is a very important parameter for the potential lipid production. Some researchers have demonstrated that oils content increase from 18 to $46 \%$ when
$\mathrm{C} / \mathrm{N}$ ratio increase from 25 to 70 [33].

Many factors including medium components, such us carbon and nitrogen sources as well as culture conditions (temperature, dissolved oxygen and $\mathrm{pH}$ ) have also a significant influence on biomass and oil accumulation [34-36].

The pattern of a $R$. glutinis strain in different wastewaters from fruit juice, potato and lettuce processing was described by Schneider et al. [37]. None of the wastewaters allowed for significant lipid production by $R$. glutinis due to the most important limiting factors for lipid production in the screened wastewaters seem to be the low content of available carbon sources in fruit juice and lettuce processing waters and the high content of nitrogen in potato processing waters, respectively.

Even at 30 hours, the lipid content is not significant in both strains because most of the available carbon was exhausted before nitrogen became the growth limiting factor, these results are enough to select $R$. mucilaginousa as a better candidate to reached a high lipid production in less time under this culture condition. To enhance lipid concentration and lipid productivity is necessary to increase $\mathrm{C} / \mathrm{N}$ ration in the mixture.

Table 3. Kinetic parameters of L/3-74-22 (C. tropicalis) and L/24-26-1(R. mucilaginousa) strain in vinasse/glycerol mixture with COD ratio 70:30 in $4 L$ bioreactors experiments at $30 \mathrm{~h}$.

\begin{tabular}{|c|c|c|c|c|c|}
\hline Strain & Biomass conc $(\mathrm{g} / \mathrm{L})$ & $\mu\left(h^{-1}\right)$ & Yield X/DQO & COD removal (\%) & Lipid Content (\%) \\
\hline $\mathrm{L} / 3-74-22$ & $20,9 \pm 5,4$ & $0,25 \pm 0,06$ & $0,39 \pm 0,09$ & $59,2 \pm 10,7$ & $13,6 \pm 1,40$ \\
\hline $\mathrm{L} / 24-26-1$ & $12,1 \pm 2,5$ & $0,15 \pm 0,05$ & $0,32 \pm 0,08$ & $47,5 \pm 17,7$ & $20,3 \pm 0,15$ \\
\hline
\end{tabular}




\subsection{Evaluation in Mixtures Slops/Glycerol with Different COD Ratios}

In order to know the influence of the composition of the vinasse/glycerol mixture and considering the availability of vinasse and glycerol, the evaluation of vinasse/glycerol COD ratios of $70 / 30 ; 30 / 70 ; 15 / 85$ and $5 / 95$ was carried at lab scale (by triplicate) using $C$. tropicalis and $R$. mucilaginosa strains. The initial COD was adjusted to 60 $000 \mathrm{mg} / \mathrm{L}$ and $1 \mathrm{~g} / \mathrm{L}$ of ammonium phosphate was supplemented to all media. Duplicated samples were analysed for dry mass, chemical oxygen demand and percentages of lipids. Figure 4 (A and B) shows a resume of the obtained results.

Unlike the behavior of these strains in glycerol, in these mixtures $C$. tropicalis cells reached higher concentrations relative to $R$. mucilaginousa. The maximum biomass concentration $(15,4$ and $10,7 \mathrm{~g} / \mathrm{L})$ and the minimum lipid content $(12,2$ and $18,5 \%)$ of both strains were achieved in presence of $70 / 30$ vinasse/glycerol mixture due to a higher nitrogen concentration in this mixture. Nevertheless, there was not significative variation between lipid concentrations of each strain in the different mixtures. Considering that mixture with 5:95 COD ratio has the higher $\mathrm{C} / \mathrm{N}$ molar ratio, it is expected that the maximum lipid content of both strains was reached in this mixture ( 27,7 and $36,8 \%$, respectively) while the maximum lipid concentration was reached in mixture with 30/70 COD ratio (Figure 2).

The higher values of COD removal were attained in mixtures with higher vinasse proportion in both strains (Table 3). These results responded to the fact that there are different compounds in vinasse as glucose, ethanol, fructose and arabinose among others that could be more easily assimilated by these yeasts instead glycerol due to the different metabolic pathways involved in their assimilation [38].

\section{A}

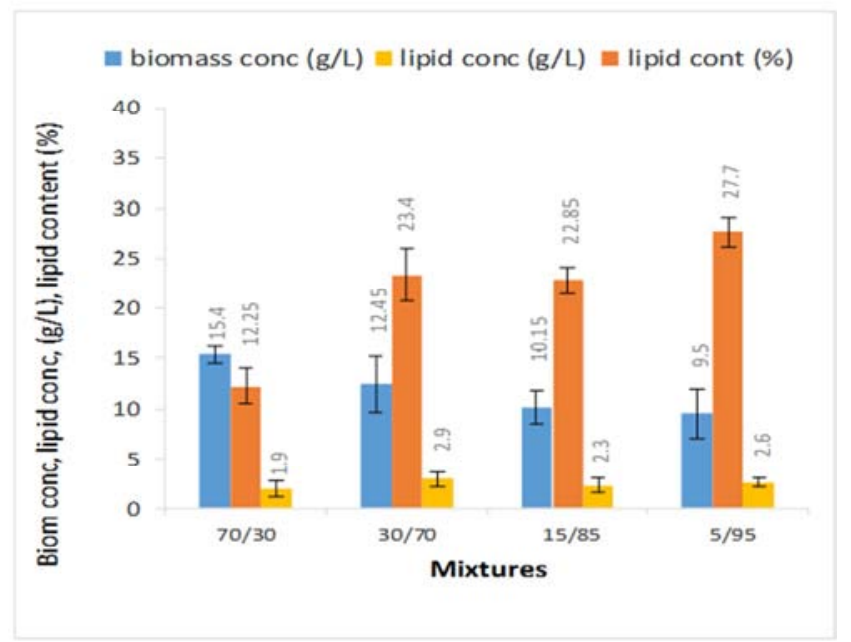

B

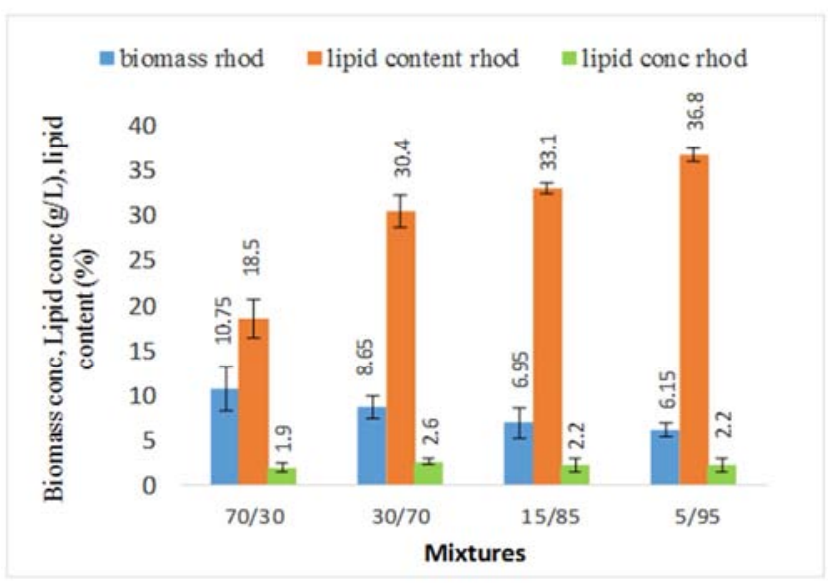

Figure 2. Biomass concentration, lipid concentration and lipid content comparison between different vinasse/glycerol mixture compositions. A: $C$. tropicalis, B: R. mucilaginousa.

According with results showed in Table 3, C. tropicalis strain achieved higher COD removal respect to $R$. mucilaginousa during these assays, although the API results showed fewer assimilated substrates by $C$. tropicalis strain. These results is expected considering that $C$. tropicalis reached higher cell concentrations due to probably differences in the anabolic and catabolic process during cultivation of each specie yeasts. The presence of inhibitory compounds from vinasse as acetic acid, furfural, hydroxymethyl furfural,vanillin, and syringealdehyde could have toxic effects on microbial cell growth, metabolism, as well as on lipid accumulation, presenting challenge in biological conversion of biomass.[39-42]. It is demonstrated that furfural and its derivatives imposed major inhibition on cell growth and lipid production of $R$. toruloides $\mathrm{Y} 4$.

Table 4. Effect of vinasse/glycerol COD ratio over growth, COD remotion and lipid concentration of L/3-74-22 (C. tropicalis) and L/24-26-1(R. mucilaginouse) strains at $48 \mathrm{~h}$.

\begin{tabular}{lllll}
\hline \multirow{2}{*}{$\begin{array}{l}\text { vin/glyc COD } \\
\text { ratio }\end{array}$} & \multicolumn{2}{c}{ Lipid conc $(\mathbf{g} / \mathbf{L})$} & \multicolumn{2}{c}{ COD removal (\%) } \\
\cline { 2 - 5 } & $\mathbf{L} / \mathbf{3 - 7 4 - 2 2}$ & $\mathbf{L} / \mathbf{2 4 - 2 6 - 1}$ & $\mathbf{L} / 3-74-22$ & L/24-26-1 \\
\hline $70 / 30$ & $1,9 \pm 0,8$ & $1,9 \pm 0,5$ & $77,5 \pm 5,4$ & $52,3 \pm 3,2$ \\
$30 / 70$ & $2,9 \pm 0,7$ & $2,6 \pm 0,3$ & $76,7 \pm 3,8$ & $49,5 \pm 1,4$ \\
$15 / 85$ & $2,3 \pm 0,7$ & $2,2 \pm 0,7$ & $60,0 \pm 8,2$ & $45,8 \pm 2,7$ \\
$5 / 95$ & $2,6 \pm 0,5$ & $2,2 \pm 0,8$ & $54,6 \pm 3,4$ & $40,1 \pm 3,6$ \\
\hline
\end{tabular}

\subsection{Analysis of Fatty Acid Composition}

Table 5 summarizes the fatty acid composition of oils obtained from $C$. tropicalis L/3-74-22 and R. mucilaginouse L/24-26-1 in vinasse/glycerol mixtures with $70 / 30$ and $5 / 95$ COD ratios in order to compare them with vegetable oils percentage range and to evaluate the influence of the mixture composition on it. The results indicated that fatty acids composition of lipids extracted from both strains comprising the range established of ASTM D6751 standard for vegetable oils used for biodiesel production. 
Most of the lipids from both strain correspond to oleic $(18: 1)$ and linoleic $(18: 2)$ acids followed by palmitic $(16: 0$ and stearic acid (18:0) suggesting that these mixtures vinasse/glycerol could be used as appropriated medium for biodiesel production from these microbial oils. This profile is similar to that of Rhodosporidium toruloides Y2 cultured in bioethanol wastewater and of Jatropha curcas L., Cryptococcus curvatus and R. toruloides Y4 oils [43]

Oleaginous strains can accumulate different type of lipids because according to the medium composition they can substitute their fatty acids in triglyceride and change their lipid composition [44].

Table 5. Fatty acids composition (\%) of lipids extracted from C. tropicalis and R. mucilaginousa strains cultured in $70 / 30$ and $5 / 95$ vinasse/glycerol mixtures compared with vegetable oils used for biodiesel production.

\begin{tabular}{|c|c|c|c|c|c|}
\hline \multirow{2}{*}{ C16 - C18 fatty acids (\%) } & \multicolumn{2}{|c|}{ C. tropicalis } & \multicolumn{2}{|c|}{ R. mucilaginousa } & \multirow{2}{*}{ Vegetable oils for biodiesel } \\
\hline & $70 / 30$ & $5 / 95$ & $70 / 30$ & $5 / 95$ & \\
\hline Palmitic acid (C16:0) & 21,5 & 8,57 & 12,77 & 12,6 & $3,5-42,6$ \\
\hline Palmitoleic acid (C16:1) & 5,19 & nd & 0,62 & 0,56 & $0,1-0,7$ \\
\hline Stearic acid (C18:0) & 3,6 & 7,45 & 7,58 & 5,18 & $0,9-24,5$ \\
\hline Oleic acid(C18:1) & 35,12 & 38,9 & 36,05 & 49,37 & $13,3-54,1$ \\
\hline Linoleic acid (C18:2) & 22,9 & 43,43 & 41,04 & 28,45 & $10,0-77,0$ \\
\hline Linolenic acid (C18:3) & 5,18 & nd & nd & nd & $0,2-6,3$ \\
\hline Total $(\%)$ & 93,49 & 98,35 & 98,4 & 95,61 & \\
\hline
\end{tabular}

nd: not detectable

\section{Conclusions}

Evaluation of C. tropicalis and R. mucilaginousa strains in vinasse/glycerol mixtures demonstrated that it is possible to develop a fermentation strategy where different composition of vinasse/glycerol mixtures could be used for microbial oil production reaching COD removal around a $50 \%$ in batch operation. Future research efforts should be done in order to further increase the lipid production focused on the optimization of media and fermentation conditions to increase lipid production and COD removal, evaluation of fed batch and continuous fermentation and developing a strategy to pick up strains with high potential to assimilate inhibitors present in vinasse and raw glycerol.

\section{Abbreviations}

TAG: Triacylglycerol

SCP: Single Cell Protein

API: Analytical Profile Index

YPG: yeast extract, $10 \mathrm{~g} / \mathrm{L}$; peptone, $20 \mathrm{~g} / \mathrm{L}$ and glucose $20 \mathrm{~g} / \mathrm{L}$

COD: Chemical oxygen demand

GC: Gas chromatography

$\mathrm{Y}_{\mathrm{X} / \mathrm{DQO}}$ : Biomass coefficient, grams of biomass/grams of chemical oxygen demand

C/N: Carbon/Nitrogen Molar ratio

\section{Acknowledgements}

The authors would like to express their appreciation to enterprise group AZCUBA (Havana, Cuba) for their financial support for this work as part of the research project "Development of advanced technologies for the treatment of residual sugar industry and its derivatives".

\section{References}

[1] Meng, X., Yang, J., Xu, X., Zhang, L., Nie, Q., Xian, M., 2008. Biodiesel production from oleaginous microorganisms. Renewable Energy XXX, 1-5.

[2] Harrigan, W. F, MacCance, M. E., 1966. Métodos de Laboratorio en Microbiología. Editorial Academia León (España) ISBN 10: 0123260507 ISBN 13: 978012326050.

[3] Mahua, T., Chatterjee, A., Seunath, A., Brendan Curran P. G., 2000. Cellular lipid composition influences stress activation of the yeast general stress response element. Microbiology 146, 877-884.

[4] Dai, C., Tao, J., Xie, F., Daí, Y., Zhao, M., 2007. Biodiesel generation from oleaginous yeast Rhodotorula glutinis with xylose assimilating capacity. Afr. J. Biotechnol. 6: 2130-2134.

[5] Odds, F. C., Bernaerts, R., 1994. CHROMagar Candida a new differential isolation medium for presumptive identification of clinically important Candida species. J. Clin. Microbial. 32, 1923-1929.

[6] Almazán O. A., 1968. Utilización de los mostos residuales para la producción de levadura de forraje (torula) ICIDCA Sobre los deriv. 2 (2), 17-26.

[7] Martínez, J. A., Almazán O. A., Saura G., Otero, M. A., 2004. Production of fodder yeast from stillage: an environmental approach. Zuckerindustrie 129 (2), 92-95.

[8] Otero, M. A., Saura G., Martínez J. A., Almazán, O. A., 2007. Fodder yeast production: a new approach for vinasse treatment. Proc. Int. Soc. Sugar Cane Technol. 26, 1127-1133.

[9] Saura, G., Valdés, I. F., Martínez, J. A., Reyes, E., Pascual, A., Otero, M. A., 2002. Tecnología de producción de levadura utilizando vinazas de destilería como fuente mayoritaria de carbono y energía. Sobre los deriv. 36 (1), 20-23. 
[10] Conde, J., Bartok, J., Reyes, A., 1978. A rapid method for the determination of Chemical Oxygen Demand. Sobre los Derivados 12, 21-26.

[11] Bligh, E. G., Dyer, W. J., 1959. A rapid method of total lipid extraction and purification. Can. J. Biochem. Physiol. 37, 911-917.

[12] Guamán-Burneo, C., Carvajal-Barriga, J., 2009. Caracterización e identificación de aislados de levaduras carotenogénicas de varias zonas naturales del Ecuador. Universitas Scientiarum, 14 (2-3), 187-197.

[13] Cazetta, M. C., Celligoi, M., 2006. Estudo de diferentes combinações de melaço/ vinhaça como substrato para produção de proteínas e lipídios por microrganismos; Ciências Exatas e Tecnológicas, Londrina, 27(1), 3-35.

[14] Faife, E., Otero M. A., Alvarez A., Peña, M. A., Melfi, M., Matos, M. L., Kozlowki, A. M., 2011. Microbial oil production by oleaginous yeasts on wastewaters-based medium. Int. Sugar Journal 113 (1355), 786-791.

[15] Karatay, S. G., Donmez, G., 2010. Improving the lipid accumulation properties of the yeast cells for biodiesel production using molasses. Bioresource Technology 101, 7988-7990.

[16] Liang, X. A., Dong, W. B., Miao X. J., Dai C. J., 2006. Production technology and influencing factors of microorganim grease. Food Res. Dev. 27 (3), 46-47.

[17] Linares, M. J., Solís, F., 2007. Rev. Iberoam. Micol. -Chapter 11-ISBN: 978-84-611-8776-8.

[18] Liu, S. J., Yang, W. B., Shi, A. H., 2000. Screening of the high lipid production strains and studies on its flask culture conditions. Microbiol. 27 (2), 93-97.

[19] Yi-Ysu, J., 2012. Maximizing biodiesel production from Yarrovia Lipolytica Polg biomass using subcritical water pretreatment. Bioresource Technology 111, 201-207.

[20] Easterling, E. R., French, T., Hernández, R. W., Licha, M., 2009. The effect of glycerol as a sole and secondary substrate on the growth and fatty acid composition of Rhodotorula glutinis. Bioresour. Technol. 100 (8), 356-361.

[21] Pan, L.-X., Yang, D.-F., Shao, L., Li, W., et al., 20019. Isolation of the oleaginous yeasts from the soil and studies of their lipid producing capacities. Food Technol. Biotechnol. 47, 215-220.

[22] Papanikolaou, S., Aggelis, G., 2002. Lipid production by Yarrowia lipolytica growing on industrial glycerol in a singlestage continuous culture. Bioresource Technol. 82(1), 43-49.

[23] Yonghong, L., Zhao Z., Fengwu B., 2007. High-density cultivation of oleaginous yeast Rhodosporidium toruloides Y4 in fed-batch culture. Enzyme and Microbial Technology 41, 312-317.

[24] Raimondi, S., Rossi, M., Leonardi, A., Bianchi, M. M., Rinald T. and Amaretti A., 2014 Getting lipids from glycerol: new perspectives on biotechnological exploitation of Candida freyschussii. Microbial Cell Factories 2014, 13:83doi:10.1186/1475-2859-13-83.

[25] Chatzifragkou, A., Makri, A., Belka, A., 2011. Biotechnological conversions of biodiesel derived waste glycerol by yeast and fungal species. Energy 36, 1097-1108.
[26] Liang, Y., Cui, Y., Trushenski, J., Blackburn, J. W., 2010. Converting crude glycerol derived from yellow grease to lipids through yeast fermentation. Bioresour. Technol. 101, $7581-7586$.

[27] Saenge, C., Cheirsilp, B., Suksaroge TT and Bourtoom, T., 2011. Potential use of oleaginouse red yeast Rhodotorula glutinis for the bioconversion of crude grycerol from biodiesel plant to lipids and carotenoids. Proced Biochem 46, 210-218.

[28] Taccari, M., Canonico, L., Comitini,F., Mannazzu I., Ciani, M., 2012. Screen of yeasts for growth on crude glycerol and optimization of biomass production. Biores. Technol. 110, 448-495.

[29] Easterling, E. R., French, T., Hernández, R. W., Licha, M., 2009. The effect of glycerol as a sole and secondary substrate on the growth and fatty acid composition of Rhodotorula glutinis. Bioresour. Technol. 100 (8), 356-361.

[30] Papanikolaou, S., Muniglia, L., Chevalot, I. Aggelis, G. and Marc, I., 2002. Yarrowia lipolytica as a potential producer of citric acid from raw glycerol. Journal of Applied Microbiology 92, 737-744.

[31] Nigam P. S., Singh A., 2011. Production of liquid biofuels from renewable resources. Progress in Energy and Combustion Science 37, no. 1, 52-68.

[32] Papanikolaou, S., Aggelis, G., 2011. Lipids of oleaginous yeast. Part I. Biochemistry related with single cell oil production," Journal of Lipid Science and Technology 113, no. 8, 1031-1051.

[33] Hassan, M., Blanc, P. J., Granger, L.-M., Pareilleux, A., Goma, G. 1996. Influence of nitrogen and iron limitations on lipid production by Cryptococcus curvatus grown in batch and fedbatch culture Process Biochem. 31 (4), 355-361(7).

[34] Chen F. and Johns M. R., 1991. Effect of C/N ratio and aeration on the fatty acid composition of heterotrophic Chlorella sorokiniana. Journal of Applied Phycology 3, 203209.

[35] Kitcha S. and Cheirsilp B., 2011. Screening of Oleaginous Yeasts and Optimization for Lipid Production Using Crude Glycerol as a Carbon Source. Energy Procedia 9, 274 - 282.

[36] Kong, X. L., Liu, B., Zhao, Z. B., Feng, B., 2007. Microbial production of lipids by cofermentation of glucose and xylose with Lipomyces starkeyi. Chin. J. Bioprocess Eng. 5 (2), 3641.

[37] Schneider T., Graeff-HönningerS., French W. T., Hernandez R.,Merkt N., Claupein W.,Hetrick M., Pham P., 2012. Lipid and carotenoid production by oleaginous red yeast Rhodotorula glutinis cultivated on brewery effluents. Energy 61, 34-43.

[38] Fakas S., Papanikolaou, S., Batsos A.,Galiotou-Panayotou, M., Mallouchos, A., Aggelis, G., 2009. Evaluating renewable carbon sources as substrates for single cell oil production by Cunninghamella echinulate and Mortierella isabellina. Biomass and Bioenergy 33, 573-580.

[39] Cheng, K. K., Cai, B. Y., Zhang, J. A., Ling, H. Z., Zhou, Y. J., Ge, J. P., Xu, J. M., 2008. Sugarcane bagasses hemicellulose hydrolysate for ethanol production by acidrecovery process. Biochem. Eng. J. 38, 105-109. 
[40] Tsigie Y. A., Wang Ch., Truong Ch. Ju Y., 2011. Lipid production from Yarrowia lipolytica Po1g grown in sugarcane bagasse hydrolysate. Bioresource Technology 102, 9216-9222.

[41] Yu, X., Zeng, J., Zheng, Y., Chen, Sh., 2014. Effect of lignocellulose degradation products on microbial biomassand lipid production by the oleaginous yeast Cryptococcus curvatus. Process Biochemistry 49, 457-465.

[42] Zhao, X., Peng F., Du, W., Liu C., Liu, D., 2012. Effects of some inhibitors on the growth and lipid accumulation
Bioprocess Biosyst Eng. 35, 993-1004 DOI 10.1007/s00449012-0684-6.

[43] Zhou W, Wang W., Li Y., Zhang Y., 2013. Lipid production by Rhodosporidium toruloides $\mathrm{Y} 2$ in bioethanol wastewater and evaluation of biomass energetic yield. Bioresource Technology 127, 435-440.

[44] Ageitos JM, Vallejo JA, Veiga-Crespo P, Villa TG., 2011. Oily yeasts as oleaginous cell factories. Applied Microbiology and Biotechnology 90(4), 1219-27. 